\title{
An Investigation of Factors Affecting E-Marketing Customers' Behavioral Intention to Use the Telecommunication Industry in Jordan
}

\author{
Mohammad Issa Al Zoubi ${ }^{1} \&$ Ahmad Issa Al Zoubi ${ }^{2}$ \\ ${ }^{1}$ Department of Business Administration, Irbid National University, Jordan \\ ${ }^{2}$ Department of Business Administration, Jordan \\ Correspondence: Ahmad Issa Al Zoubi, Department of Business Administration, Jordan. E-mail: \\ ahmadalzoubi37@gmail.com
}

Received: June 30, 2019 Accepted: July 23, 2019 Online Published: August 19, 2019

doi:10.5539/ijms.v11n3p125 URL: https://doi.org/10.5539/ijms.v11n3p125

\begin{abstract}
The main concern of any organization is the client. Telecommunication is an operation-based organization that prioritizes to discover methods for fulfilling the client's needs. Detecting this significance, this research was carried out to investigate the variables that could impact the client's behavior toward e-marketing businesses in Jordan. The researchers collected the data using the questionnaire survey method. The research result revealed that relative advantage, complexity, compatibility, electronic marketing, quality of a website, quality of mobile service and strategies were found to be significantly associated with e-marketing customers' behavioral intention to use the telecommunication industry. Additionally, Telecom owners and operators have to improve services quality as much as they could in light of the fact that it is the most significant factor of client' choices in the telecom industry in Jordan. Finally, this research can be extended to other Arab countries to enable them to comprehend the various factors that impact customers' behavior.
\end{abstract}

Keywords: consumers' attitudes, E-marketing, online marketing, referral marketing, relationship marketing

\section{Introduction}

The new innovation and Information Technology (IT) application and systems have invaded almost every single organization, office, household, school, etc. At the same time, IT-assisted organizations with their basic leadership issues, while furnished shoppers with valuable access to the website where they can find about anything they need including different products and merchants. In this way, data influences individuals' buying choices. Meanwhile, organizations gather data about customers and their preferences and predispositions to demonstrate better methodologies coupled with better choices (Lin \& Hong, 2006). Not only that, organizations may be able to improve their products, product delivery as well as customer services.

Given the significance of clients' behavior in the telecommunication business, and with the ongoing advancements in the telecommunication industry, there is a need to find a basic research motivation. Also, to understand customers' satisfaction towards the services and the variables that could impact the customers' choices and preferences of the telecom provider.

Certainly, organizations can set up their businesses on the web, which is called web-based business, and promoting the business on the web is called electronic commerce. The previously mentioned electronic-based exercises (relatively favorable position, multifaceted nature, data on e-commerce, site quality, nature of portable services and policies) must be incorporated with the general promoting technique so as to meet the goals of the electronic marketing of the organization (Reedly, Schullo, \& Zimmerman, 2000).

With respect to purchaser's behavior on the web, it can be seen that they emphasize on purchasing an item and data gathering (Moon, 2004) and scan for online services, for example, e-commerce, internet banking, contributing and e-payment (Lain \& Lin, 2007). There are numerous elements that impact buyers making a basic decision whether on the web or elsewhere.

Several years ago, the client's determination, choices, and loyalty have been considered as one of the major hypothetical and reasonable focus for most advertisers and client analysts (Dawar, 2013). Studies have focused and investigated the prior needs and demands of the customers which would then enable the marketers to tailor their product and services accordingly. Where services are concerned there is a need for it to be centralized 
especially with regards to the marketing services that are being offered in other areas and countries. It should be controlled and monitored as the process and procedures of marketing should be achievable throughout the nation as well by potential customers.

Subsequently, clients' inclination towards e-promoting is affected by lifestyle specifically (Moon, 2004), individual and other elements (Senecal \& Nantel, 2004). Alsmadi, who conducted research to examine e-shopping behavior among Jordanian consumers, concluded that the use of e-marketing was not in pace with global trends, as many consumers did not care much to purchase electronically. According to Yaseen (2019), in Jordan, there is no past investigation on clients' dispositions towards e-promoting.

Some significant issues are highlighted in the questionnaires such as learning and aptitudes of e-promoting online organizations advancements, and security measures in e-showcasing. The purpose of this study is to determine elements affecting adult clients' behaviors with e-promotion of the telecom industries in Jordan. This study is expected to examine the root of the clients' mindset in the telecommunication industry such as in Relative advantage, Complexity, data about on electronic promotion, quality of the net, Mobile Service and Strategies of Mobile Service. Indeed, this matter brings about a genuine concern in e-shopper practices. Thus, the scientist believes that this investigation will add to the general literature of e-promoting, and online purchaser behavior specifically through recognizing the elements that influence the utilization of e-promotion in Jordan.

In any organization, working location and workplaces are ever changing due to the macroeconomic variables like technology. This has forced firms in the telecommunication industry to adjust themselves and accommodate changes in the external environment for meeting the growing desires of clients. For the case of Jordan, the telecommunication industry implements electronic marketing practices to enable customers to easily interact with the organization. This helps in improving responses to problems and management of service quality.

At the time of this study, there was no study known to the researcher conducted in the Jordan telecommunication industry. Though there is a lack of promotion on electronic marketing among the customers, the Jordan telecommunication industry has adopted electronic marketing as a means of customer retention in the Jordan market. Hence, this is the research gap that needs to be filled. Given the novelty of electronic marketing in the mobile industry, this study is therefore sought to address this gap by addressing the research question: What are the components affecting shoppers' approaches towards e-promoting in the mobiles telecommunications field in Jordan companies?

\section{Literature Review}

There are various acknowledged hypothetical frameworks that have been utilized by analysts to examine the reception and dissemination of data innovation and new technologies by the organizations and companies. These frameworks showed solid argument that empowers administrators and specialists, as well as a scholarly community, to understand and be knowledgeable about the applications and capability of new Internet innovations so that they can be utilized skilfully (Karahanna \& Straub, 1999). Additionally, a later investigation into information technology reception and use has been prompted by the need to evaluate factors that can lead to effective use of promotion (Lynn et al., 2002; Rose \& Straub, 1998).

The most relevant speculations by the researchers of the area are the Rogers (1995) Innovation Diffusion Theory (IDT), Davis (1989) Technology Acceptance Model (TAM), and the Decomposed Theory of Planned Behavior model (DTPB) Looi, (2004). Among these models, The IDT and TAM models have given a decent commitment towards understanding the recognition, utilization, and dispersion of innovations. These models have been tested in a wide range of technology and have been acknowledged as effective models. To lead this exploration, only the initial two models will be considered, innovation TAM and IDT. This is because E-promotion is another kind of end-client data framework that is intensely founded on the telecommunication technology.

While reviewing the literature, it is noticed that there are a limited number of studies conducted to integrate the IDT and TAM in the field of E-Marketing. Accordingly, there is a need to conduct more studies to investigate the theory from an E-promotion perspective. Although these models have been considered as important factors to illustrate the diffusion of new technologies and acceptance, they ignore some other important factors both within and outside the organization that may have an impact on E-Marketing adoption. Therefore, when implementing these models to study the adoption of E-Marketing, the model needs to be expanded to include some other factors. Hence, besides IDO and TAM, Information on E-marketing, Website Quality, Quality of Mobile Service and Strategies factors will be other factors that will be used in this study.

\section{Research Methodology}

The Conceptual Framework of this study consists of two types of variables namely, independent and dependent 
variables as shown Figure 1 below.

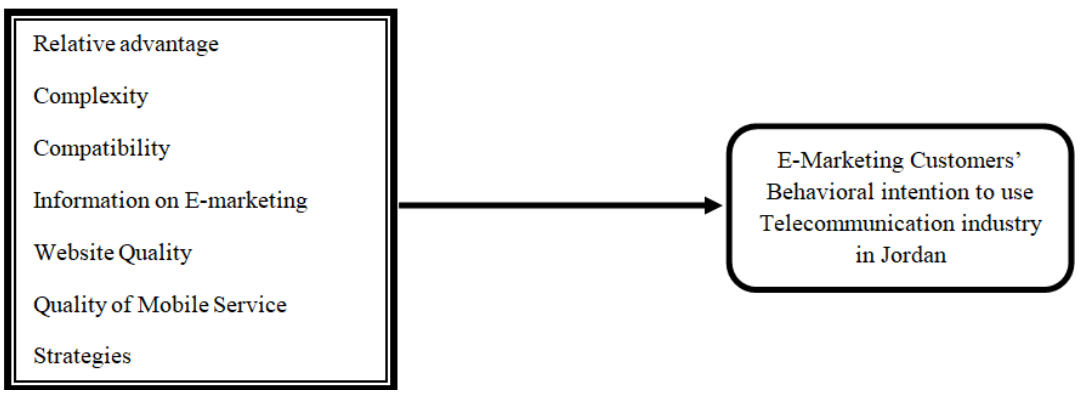

Figure 1. Conceptual framework

\section{Research Hypothesis}

The study is designed to test the following hypotheses:

$\mathrm{H}_{1}$ : There is no statistically significant affect of the Relative advantage on Customers' Behavioral intention toward e-marketing at Jordan mobiles telecommunication sector.

$\mathrm{H}_{2}$ : There is no statistically significant affect of the Complexity on Customers' Behavioral intention toward e-marketing at Jordan mobiles telecommunication sector.

$\mathrm{H}_{3}$ : There is no statistically significant affect of the Compatibility on Customers' Behavioral intention toward e-marketing at Jordan mobiles telecommunication sector.

$\mathrm{H}_{4}$ : There is no statistically significant affect of the Information on Customers' Behavioral intention toward e-marketing at Jordan mobiles telecommunication sector.

$\mathrm{H}_{5}$ : There is no statistically significant affect of the Website Quality on e-marketing on Customers' Behavioral intention toward e-marketing at Jordan mobiles telecommunication.

$\mathrm{H}_{6}$ : There is no statistically significant affect of the Quality of Mobile Service on Customers' Behavioral intention toward e-marketing at Jordan mobiles telecommunication sector.

$\mathrm{H}_{7}$ : There is no statistically significant affect of the Strategies on Customers' Behavioral intention toward e-marketing at Jordan mobiles telecommunication sector.

\section{Sample \& Population}

The number of samples in this research comprises of all customers of the Jordanian telecommunication companies. Since most of the Jordanians own mobile gadgets, it is only proper to have a suitability test to gather the required information. The sample of this research comprises of (600) customers respectively among four telecommunications firms in Jordan: Orange, Zain, Umniah. Two hundred customers were chosen from each organization and along these lines, 600 customers were approached. Questionnaires were handed out to test individuals and the 569 working responses were gathered.

\section{Approaches of Collection}

Secondary information is one of the main sources for this research which relies upon information that includes hypothetical criticism which is identified with the subject of the research, and accumulated to fabricate hypothetical base of this study. The source of information includes course books, past research, Internet, and other accessible sources. The second source was the primary information. Those were gathered explicitly with the end goal of this research, by devising a questionnaire adapted from Alzoubi et al. (2017) and Al-Madi et al. (2012) to gather the important information. However, data were collected using survey questionnaires that were sent to respondents by hand. The population of the current study is the customers respectively among four telecommunications firms in Jordan. This study managed to employ 600 customers from the target population. Random sampling method was adopted to select the number of customers from each telecommunication at Jourdan. Only 569 questionnaires were returned representing 94 percent of the total number of questionnaires being distributed 


\section{Results}

Various regress investigations were carried out to discover the response to the investigation question and hypothesis testing. Numerous regressions distinguish the general commitment of every factor and decide the best indicator factors among the various factors. For instance, R2 demonstrates how well a group of factors (Relative advantage, Complexity, Compatibility, Information on E-marketing, Website Quality, Quality of Mobile Service and Strategies) are competent to determine certain outcomes (client adoption). R2 standard value is equal to 1, and it implies that the continuous dependent element and various autonomous factors have a direct relationship, while a zero value of $\mathrm{R} 2$ implies there is no direct relationship. The main phase of regression model investigation demonstrates R2 value of 0.638 (shown in Table 1) which shows that the variables give a $63.8 \%$ fluctuation of client selection. Standard various regression additionally gives a balanced R2 value that "rectifies" R2 incentive to demonstrate a high expectation of the genuine corrects rates (Pallant, 2007).

Table 1. Results of multiple regressions between factors and customers' behavioral intention

\begin{tabular}{|c|c|c|c|c|c|}
\hline $\begin{array}{l}\text { Model } \\
1\end{array}$ & $\begin{array}{l}\mathrm{R} \\
.785^{\mathrm{a}}\end{array}$ & $\begin{array}{l}\text { R Square } \\
.638\end{array}$ & $\begin{array}{l}\text { Adjusted R square } \\
.620\end{array}$ & \multicolumn{2}{|c|}{$\begin{array}{l}\text { Std. error of the estimate } \\
.615\end{array}$} \\
\hline \multirow[t]{2}{*}{ Model } & \multicolumn{2}{|c|}{ Unstandardized coefficients } & Standardized coefficients & $\mathrm{t}$ & Sig. \\
\hline & $\mathrm{B}$ & Std. Error & Beta & & \\
\hline (Constant) & 1.133 & .246 & & 4.481 & .000 \\
\hline $\mathrm{H} 1$ & .113 & .032 & .258 & 2.704 & .004 \\
\hline $\mathrm{H} 2$ & .115 & .035 & .245 & 2.340 & .000 \\
\hline H3 & .106 & .053 & .249 & 2.234 & .006 \\
\hline $\mathrm{H} 4$ & .145 & .037 & .294 & 2.276 & .001 \\
\hline H5 & .045 & .045 & .212 & 2.283 & .002 \\
\hline H6 & .004 & .039 & 207 & 2.084 & .003 \\
\hline H7 & .004 & .047 & .217 & 2.084 & .000 \\
\hline
\end{tabular}

\section{Tests of Hypothesis}

The main goal of this study is to identify which factors within the model have the most significant impact on the dependent variable utilizing the Beta value. The commitment of each independent variable within the model has been compared and the hypothesis of this subject related to the relationship of the seven components of users. The hypothesis testing leads to meeting the objectives. These discoveries illustrate that relative advantage incorporates a significant impact on E-marketing utilization among grown-up clients $(\beta=.113, \mathrm{p}=.000)$.

Complexity appeared to have a significant impact on Electronic Marketing Adoption among adult Customer ( $\beta$ $=.115, \mathrm{p}=.000)$. Compatibility showed an essential direct impact on Electronic Marketing Adoption among adult Customer $(\beta=.106, p=.000)$. Information on E-marketing was shown to have a significant direct effect on Electronic Marketing Adoption among adult Customer ( $\beta$ is equal to 0.145 , p is equal to 0.000 ). Site Quality was appeared to have a significant impact on Electronic Marketing Adoption among adult Customer $(\beta=.045$, $\mathrm{p}=.000$ ). Additionally, Quality of Portable Benefit also had a significant impact on Electronic Promoting Adoption among grown-up Client $(\beta=.004, p=.000$ ). Lastly, Strategies showed an essential direct impact ( $\beta$ is equal to $0.004, \mathrm{p}$ is equal to 0.000 ) Electronic Marketing Adoption among adult Customer.

\section{Conclusion and Recommendations}

This research arises to investigate the factors impacting client reception of the telecom industry in Jordan. Various regress investigations are carried out in this research to discover essential factors that lead to client reception in the telecom industry. In light of past literature, five (5) essential factors of client adoption were recognized. The outcomes show four factors essentially affecting the client adoption in particular Relative favorable position, Complexity, Compatibility, and Information on E-marketing, Website Quality, Quality of Mobile Service and Strategies keys related to clients' choice in Jordanian's telecom companies.

Exchanging Relative preferred standpoint is an irrelevant factor in creating client selection in the telecom industry in Jordan. The findings of similar research demonstrate that quality of service is the biggest factor of client adoption in the telecom industry. Hence, telecom operators should concentrate on Relative preferred standpoint, Compatibility, Complexity, Information on E-promoting, Website and Mobile quality, Service and policies with the end goal of client retention and developing client preferences.

Telecom owners and operators have to improve services quality as much as they could in light of the fact that it 
is the most significant factor of client' choices in the telecom industry in Jordan. To be at an unmistakably attractive spot at the top of the priority list of target clients, telecom services should give more focus on solid system coverage, rare call drops, and voice clearness in the developed system. A satisfied client is the best promotion for the company. Telecom owners and operators have to give all sorts of refreshed promotions and customer preferences such as customers' special privileges. They should assemble a trustworthy company with steadfast clients by offering guaranteed telecom services with no cover charge. A strong relationship between telecom operators and clients is the best approach to attract clients' choice of telecom operator, although when competitors attempt to lure them with lower costs.

In addition, this research will be an added value and information on the clients' assurance of the telecommunication companies in the served communities, particularly to the wealthy Middle Easterner locale. Despite the lack of inquiring on this matter in Jordan, the overall outcome of this research will benefit the service operator to enhance Customers' Behavioral Intention. In addition, as resulted from the study outcomes, the suppliers have to develop methodologies to improve their brand image and address issues relating to clients' patterns of purchasing behavior. Nevertheless, this research does have a few constraints. Hence to overcome these restrictions, more factors such as satisfaction, perceived value, switching barrier on client loyalty, statistic qualities of clients, life cycles, as well as portable administrations, can be investigated further to comprehend their impact on brand loyalty in Jordan. Finally, this research can be extended to other Arab countries to enable them to comprehend the various factors that impact customers' behavior.

\section{References}

Alsmadi. (2002). Consumer Attitudes Toward Online Shopping in Jordan: Opportunities and Challenges. Forum on Marketing in the Arab World, Sharjah, UAE.

Alzoubi, S. I., \& Alzoubi, A. I. (2017). Investigating the Extent of Learning Management System Adoption in a Jordanian. International Journal of Business and Social Science, 8(1), 208-216.

Davis, F. D. (1989). Perceived usefulness, perceived ease of use, and user acceptance of information technology. MIS Quarterly, 13(3), 319-340. https://doi.org/10.2307/249008

Dawar, P. (2013). A Study of Factors Affecting Customer Satisfaction In Present Highly Competitive Banking Industry. Asia Pacific Journal of Marketing, 2(2).

Karahanna, E., Straub, D., \& Chervany, N. L. (1999). Information Technology Adoption Across Time: A Cross-Sectional Comparison of Pre-Adoption and Post-Adoption Beliefs. MIS Quarterl, 23(2), 183-213. https://doi.org/10.2307/249751

Keerthi, K. M. (2018). Influence of Digital Marketing on Consumer Purchase Behavior. IJTSRD, 3(1), 836-839. https://doi.org/10.31142/ijtsrd19082

Lain, J. W., \& Lin, T. M. (2007). Effects of Consumer Characteristics on their Acceptance of Online Shopping: Comparisons among Different Product Types. Computer in Human Behavior, 24(2), 48-65. https://doi.org/10.1016/j.chb.2007.01.002

Lin, \& Hong. (2006). Using Consumer Knowledge in Designing Electronic Catalog. Expert Systems with Applications.

Looi, H. C. (2004). A Model of Factors Influencing Electronic Commerce Adoption among SME's in Brunei Darussalam. International Journal of Information Technology, 10(3), 72-87.

Lu, J., Yu, C. S., Liu, C., \& Yao, J. E. (2003). Technology acceptance model for wireless Internet. Internet Research: Electronic Networking Applications and Policy, 23(3), 206-222. https://doi.org/10.1108/10662240310478222

Lubna, R. (2013). Online Marketing Through Consumers: A Study of Effectiveness of Various Tools and Techniques Across Industries. British Journal of Marketing Studies, 1(5), 11-23.

Miah, I., \& Abul, K. A. (2018). Factors Influencing the Customer Satisfaction on Local and Foreign Telecommunication Companies in Malaysia. International Journal of Scientific \& Engineering Research, $9(4)$.

Moon, J. (2004). Consumer Adoption of the Internet as an Information Search and Product Purchase Channel: Some Research Hypotheses. International Journal Internet Marketing and Advertising, 1(1), 104-118. https://doi.org/10.1504/IJIMA.2004.003692

Nidhi, T., \& Simran, K. (2018). Impact of Digital Market on Consumer Buying Behaviour. National Journal, 
$8(2)$.

Pallant, J. (2007). SPSS survival manual: a step by step guide to data analysis using SPSS for Windows. Crows Vest: Allen and Unwin.

Reedly, S., \& Zimmerman. (2000). Electronic Marketing: Integrating Electronic Resources into the Marketing Process. Harcourt.

Richarme. (2001). Consumer Decision Making Models. Strategies and Theories, Oh My! Decision Analyst, 2(16), 55-76.

Rogers, E. M. (1995). Diffusion of innovations. Free Press.

Rose, G., \& Straub, D. (1998). Predicting general IT use: Applying TAM to the Arabic world. Journal of Global Information Management, 6(3), 39-46. https://doi.org/10.4018/jgim.1998070104

Senecal, S., \& Nantel, J. (2004). The Influence of Online Product Recommendation on Consumers Online Choice. Journal of Retailing, 159-169. https://doi.org/10.1016/j.jretai.2004.04.001

Victor, V., Thoppan, J. J., Nathan, R. J., \& Maria, F. F. (2018). Factors Influencing Consumer Behavior andProspective Purchase Decisions in a Dynamic Pricing Environment. Social Sciences, 1(1), 1-14. https://doi.org/10.3390/socsci7090153

\section{Copyrights}

Copyright for this article is retained by the author, with first publication rights granted to the journal.

This is an open-access article distributed under the terms and conditions of the Creative Commons Attribution license (http://creativecommons.org/licenses/by/4.0/). 